\title{
Effect of sample to sugar syrup solution ratio on osmotic drying behaviour of banana
}

\author{
Durvesh Kumari ${ }^{1}$ and Samsher ${ }^{2}$ \\ 1 Sri Vankateswara University, Gajraula \\ ${ }^{2}$ Deptt. of Agric. Engg and Food Technology, SVPUA\&T, Meerut (UP) \\ Email: durgesh14@yahoo.co.in
}

\begin{abstract}
The purpose of this work is to analyze the effect of sample to sugar syrup solution ratio of osmotic drying behaviour of banana as moisture loss, solid gain and water loss during osmotic dehydration. Banana slice of $8.0 \mathrm{~mm}$ thickness were immersed in sugar syrup concentration of $50 \%(\mathrm{w} / \mathrm{w})$ in the sample to sugar syrup ratio of 1:2, 1:4 and 1:6 for 180 minutes at 300C temperature. The study was investigated in order to determine optimum sample to sugar syrup solution ratio of banana as pretreatment followed by mechanical drying in hot air oven. Studies were also carried out to investigate the hot air oven drying behavior of osmotically dehydrated banana slices. Percent moisture loss, weight loss and solid gain increased with decreased with slice thickness then increased. Drying rate increased with increase in slice thickness.
\end{abstract}

Key words: osmotic dehydration, banana, solid gain, moisture loss, weight loss

Fresh fruit and vegetables contain 75 to $95 \%$ water and one way to reduce the water content initially is to use osmotic dehydration. The difference in osmotic pressure of the immersion solution and the product is the driving force of the process. Often used solutes are sugar solutions, 30 to 50 Brix, or various salt solutions (Gekas and Mavroudis, 1998). The osmotic dehydration step can remove up to $50 \%$ of the water in the original fruit or vegetable. The product will lose water and most often gain solutes from the immersion solution. To achieve a stable product with a long shelf life requires a final stage of convection air drying, vacuum drying or microwave-assisted drying.

Bananas are considered the fourth most important food crop in the world, after the three main cereals rice, wheat and corn. Although fresh bananas are widely consumed in developed countries, the consumption of processed banana products is less than that of other processed fruits. Banana figs produced by sun-drying ripe bananas may be one of the oldest processed food products. After banana figs, the next processed banana products were apparently dehydrated flakes and powder. Banana puree is at present the highest volume processed banana product.
Osmotic dehydration (OD) is a water removal technique, which is applied to horticultural products such as fruits and vegetables to reduce the water content while increasing soluble solid content (Kaymak-Ertekin and Sultanoglu, 2000). The raw material is placed into concentrated solutions of soluble solids having higher osmotic pressure are caused by the water and solute activity gradients across the cell membrane, the cell wall and the surface of the tissue. The complex cellular structure of food acts as a semi-permeable surface. Since these compartments are only partially selective, there is always some solute diffusion into the food.

The water transfer is generally accompanied by natural substances (vitamins, flavours, fruit acids, pigments, saccharides and mineral). As consequence of this exchange, the product loses weight and shrinks. OD as a pretreatment to many processes improves nutritional, sensorial and functional properties of food without changing its integrity. It is effective even at ambient temperature, so heat damage to texture, colour and flavour of food is minimized (Rastogi and Raghavarao, 1997). Chandra and Kumari (2011) studied 
on the effect of sample to sugar syrup ratio on osmotic dehydrated banana slices. Moisture content decreased more rapidly during initial stage of drying as compared to later part of drying in both drying conditions.

The kind of sugar and its concentration as osmotic substance strongly affect the kinetics of water removal, the solid gain and the equilibrium water content. As studied by Ponting et al., 1966); Contreras and Smyrl (1981); Islam and Flink (1982); Videv et al., (1990); Heng et al., (1990); Biswal et al., (1991) and Sharma et al., (1991) that by increasing the molar mass of solute, weight loss and dehydration aspects of the process are favoured and both equilibrium and drying rate increases with the increase of osmotic syrup concentration.

The mass transfer in a system when immersing pieces of fruit is a function of the temperature and osmotic pressures of the system, the rheology of the immersion solution, the viability of the product, the geometry and structure of the product, and agitation. The viability and eventual collapse of the cell structure during immersion will determine the status of the product before the final drying (Prothon et al., 2003). Ponting et al., (1966) and Flink (1979) reported that an increase of osmotic solution to sample mass ratio resulted in an increase in both the solid gain and water loss in osmotic dehydration. To avoid significant dilution of the medium and subsequent decrease of the (osmotic) driving force during the process a large ratio (at least 30:1) was used by most workers whereas some investigators used a much lower solution to product ratio $(4: 1$ or $3: 1)$ in order to monitor mass transfer by following changes in the concentration of the sugar solution (Conway et al., 1983).

Banana may be dried in different forms by different methods (Somogyi et al., 1996; Desai, and Kotecha, 1995). Sun or solar dried bananas are used for flour or powder. To prevent darkening of the product, $\mathrm{SO}_{2}$ pretreatment is normally used. Diced or sliced and peeled bananas are dried on trays in heated air chambers or tunnels. Hot air of less than $93^{\circ} \mathrm{C}$ initially, and about $65^{\circ} \mathrm{C}$ finally, is used to dry bananas to $20 \%$ moisture content (w.b.). Freeze drying of banana slices is still not very practical, although high-quality banana granules can be produced with this method (Somogyi et al., 1996). Banana pulp is dried into flakes by drum drying, typically in double-drum atmospheric dryers. The flakes may be pulverized to make a powder. Spray dried banana powder is produced after special preparation of the feed, mainly dilution with water. Several other procedures have been developed for banana drying. One example is the osmovac process, which starts with an osmotic treatment of banana pieces in a sugar syrup of $70^{\circ}$ Brix for $8-10 \mathrm{~h}$. After the surface syrup is strained from the fruit, the pieces are dried in a vacuum dryer at $66^{\circ} \mathrm{C}-71^{\circ} \mathrm{C}$ and $10 \mathrm{~mm} \mathrm{Hg}$ to a final moisture content of $2.5 \%$.

\section{Materials and methods}

The ripe banana of uniform shape and size, firm texture and proper maturity were procured from the local market of Modipuram (Meerut). Sugar and other required material were also procured from the local market of Meerut (U.P). The ripe banana, sugar, Potassium meta-bisulphite, Stainless steel knife, Petri-dishes, beaker, and tray drier were required to conduct the experiment. Banana (Variety: Dwarf Cavendish) were selected for the present study.

Osmotic dehydration was conducted at room temperature for the banana slice thickness of $8.0 \mathrm{~mm}$, sugar syrup concentration of $50^{\circ} \mathrm{Bx}$, sample to sugar syrup ratio of 1:2,1:4, and 1:6. Banana samples of desired thickness were placed in beaker containing osmotic solution of $50 \%(\mathrm{w} / \mathrm{w})$. The beaker was placed at room temperature. After an interval of an hour, samples were removed from the beaker and wiped out by tissue paper so as to remove the sugar syrup and weighed. After weighing, samples were again placed into the beaker are kept at room temperature. This process was repeated up to three hours. At the end of 
experiment, final weights was noted and calculate the corresponding moisture content, moisture loss, weight loss and solid gain in percentage. The partially osmotically dehydrated samples were further subjected to hot air oven drier for final drying at $60^{\circ} \mathrm{C}$ temperature. The size of each sample was varies between 10.0-12.80 $\mathrm{g}$ as per slice thickness. Based on review and literature, the variables namely, osmotic temperature, sugar syrup concentration, thickness, and sample to sugar syrup ratio were selected for carrying out osmotic dehydration studies.

The kinetics of osmotic dehydration are determined by estimating the rate of water removal and that of solid gain, Generally, higher rates of water removal take place within the first 60 minutes of osmotic dehydration due to large driving force between the dilute fruit sap and osmotic solution. Kinetics of an osmotic dehydration process, total weight reduction (WR), solid gain (SG) and water loss (WL) based on initial dry matter content can be calculated according to (Sharma et al., 2000). Drying rate was calculated using following equation

\section{Results and Discussion}

Experiments were carried out to study the effect of sample to sugar syrup ratio viz. 1:2, 1:4 and 1:6 on the osmotic behaviour of banana slice of $8.0 \mathrm{~mm}$ thickness in the $50 \%$ sugar syrup concentration. The final moisture content of the samples varies 190 to $210 \%$ (db) against initial moisture content of $270 \%(\mathrm{db})$. All the samples of banana slice were osmosed to $180 \mathrm{~min}$ at room temperature.

Moisture Loss: The moisture loss in banana slice depends on the initial moisture content sugar concentration, thickness of slice, and sample to sugar syrup ratio, slice thickness and texture. The moisture loss of banana slice of $8.0 \mathrm{~mm}$ thickness decreased with increase in 1:2 to $1: 4$ sample to sugar ratio then increased with increased with 1:4 to $1: 6$ sample to sugar syrup ratio in given in Table 1 . The lowest score of moisture loss was observed in 1: 4 sample to sugar syrup ratio samples of banana slices. The moisture loss increased with increase with osmotic time.

Weight Loss: The initial weight of the sample was taken according $8.0 \mathrm{~mm}$ thickness was varied 12.80, 10.20 and $11.60 \mathrm{~g}$ for $1: 2,1: 4$ and 1: 6 sample to sugar syrup ratio, respectively. Weight loss of the samples was depended on moisture loss shown in Table 1. The maximum cumulative weight loss increases with osmotic time for the banana slice samples. The weight loss varies from 8.23 to $21.72 \%$ against the all samples in 180 min under osmosis.

Solid Gain: The solid gain of banana slice of $8.0 \mathrm{~mm}$ thickness decreased with increase in $1: 2$ to $1: 4$ samples to sugar ratio then increased with changed with $1: 4$ to 1:6 sample to sugar syrup ratio in $50 \%$ sugar syrup concentration showed in Table 1. It was clear that the solid gain increased with increased in osmotic period. This was varied from 2.88 to $7.91 \%$. Banana slice of 50 \% sugar syrup concentration was observed lowest solid gain within $60 \mathrm{~min}$ in other ones.

Osmotic dehydration behaviour: Preliminary studies indicated that the initial moisture content of the banana slice ranged between $73 \pm 1 \%(w b)$ or $270 \pm 1 \%$ on dry basis. A relationship between moisture content and osmotic time is shown in Fig. 1. After osmosis, final moisture content of the samples was ranged from 190 to 210 percent (dry basis). The moisture content of the samples decreased with increasing osmotic time. From the Table 1, it is clear that final moisture content of the samples decreased with increased in sugar syrup concentration. The osmotic dehydration was done at room temperature for $180 \mathrm{~min}$. The banana samples of $8.0 \mathrm{~mm}$ thickness with sample to sugar syrup ratio of 1:4 under $50 \%$ sugar syrup concentration were indicated that highest moisture loss and lowest in 1:4 samples (Fig. 1). 
Drying rate of banana slice plotted against osmotic time is presented in Fig.2. Drying rates of all samples were high initially when the moisture content was highest. From the Fig. 2, it in clear that drying rate was highest at $60 \mathrm{~min}$ then decreased gradually. Banana slice of 1:4 samples expressed highest drying rate during entire osmotic period followed by $1: 2$ and $1: 6$ with $8.0 \mathrm{~mm}$ slice thickness in $50 \%$ sugar syrup concentration.

Table 1: The moisture loss, weight loss and solid gain of $8.0 \mathrm{~mm}$ banana slice in $50 \%$ sugar syrup concentration at room temperature

\begin{tabular}{|c|c|c|c|c|c|c|c|c|c|}
\hline \multirow{2}{*}{$\begin{array}{c}\text { Time, } \\
\text { min }\end{array}$} & \multicolumn{3}{|l|}{ Moisture loss, \% } & \multicolumn{3}{l|}{ Weight loss, \% } & \multicolumn{3}{l|}{ Solid Gain, \% } \\
\cline { 2 - 11 } & $\mathbf{1 : 2}$ & $\mathbf{1 : 4}$ & $\mathbf{1 : 6}$ & $\mathbf{1 : 2}$ & $\mathbf{1 : 4}$ & $\mathbf{1 : 6}$ & $\mathbf{1 : 2}$ & $\mathbf{1 : 4}$ & $\mathbf{1 : 6}$ \\
\hline 0 & 0 & 0 & 0 & 0 & 0 & 0 & 0 & 0 & 0 \\
\hline 60 & 12.22 & 11.11 & 15.92 & 9.06 & 8.23 & 11.72 & 3.16 & 2.88 & 4.20 \\
\hline 120 & 18.51 & 17.03 & 24.44 & 14.06 & 12.55 & 17.93 & 4.45 & 4.48 & 6.51 \\
\hline 180 & 22.22 & 22.22 & 29.63 & 16.40 & 16.37 & 21.72 & 5.82 & 5.85 & 7.91 \\
\hline
\end{tabular}
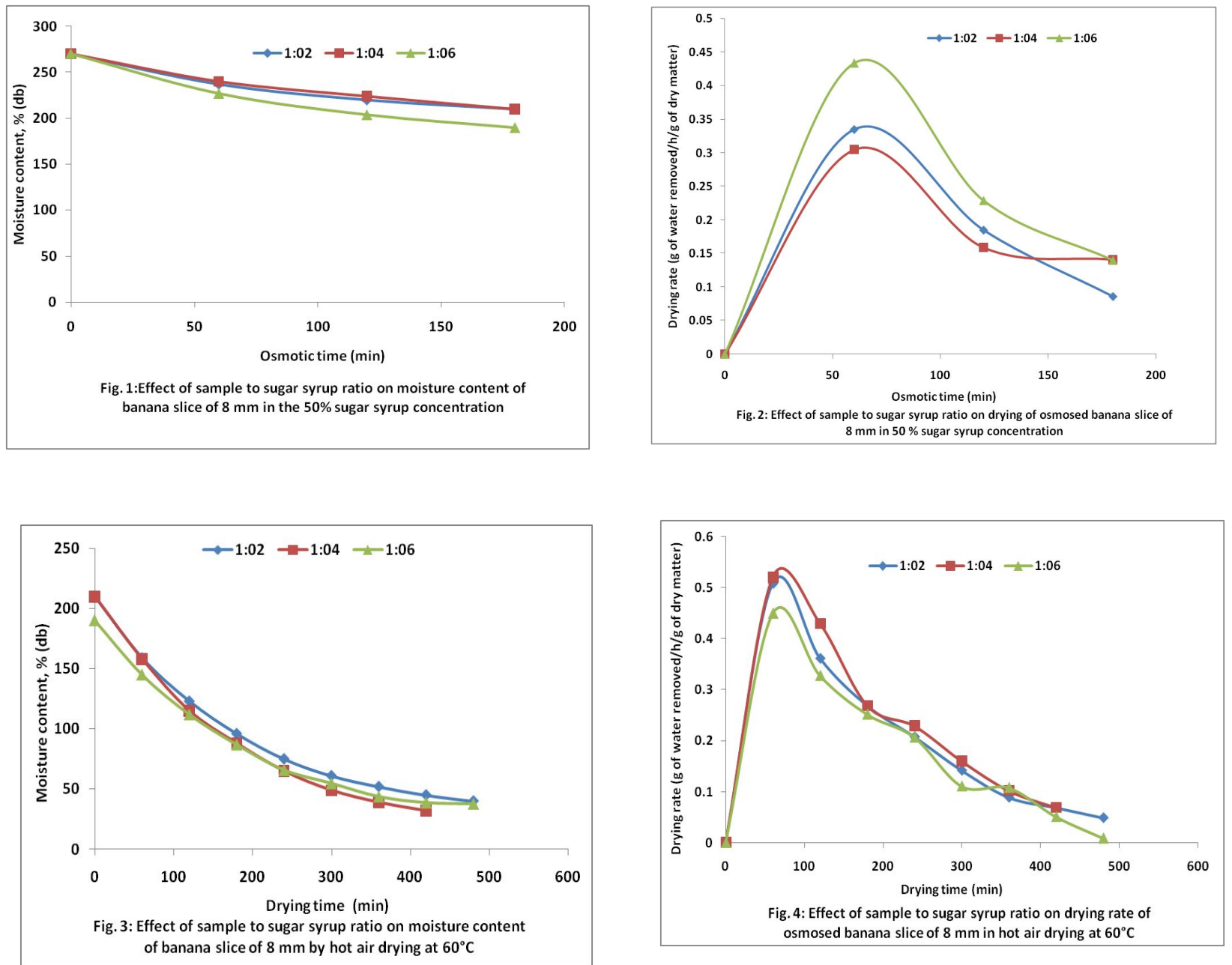
Hot air drying characteristics: Hot air drying characteristics of osmotically dehydrated banana slice were studies at $600 \mathrm{C}$ temperature in hot air oven. Samples were dried from different initial moisture content viz. 210, 210 and 190\% (dry basis) of sample to sugar syrup ratio of 1:2, 1:4 and 1:6 in 50\% sugar syrup concentration $(\mathrm{w} / \mathrm{w})$, respectively having and $8.0 \mathrm{~mm}$ thickness of banana slice. Plots for moisture content versus drying time and drying rate versus drying time are shown in Fig. 3 and Fig.4. From Fig.3, it is clear that moisture content of osmosed banana slice decrease with increasing drying time gradually. The final moisture content of the samples basically depends upon initial moisture content of the samples, if all conditions are steady. The samples were obtained final moisture content as 40, 32 and $38 \%$ (db) of sample to sugar syrup ratio of 1:2, 1:4 and 1:6 in $50 \%$ sugar syrup concentration, respectively in 420-480 $\mathrm{min}$ in hot air oven. From the Fig. 4. it is indicated that drying rate of the $50 \%$ sugar syrup concentration banana samples had fastest drying rate. Drying rate of the samples was exponentially increases upto $60 \mathrm{~min}$, and then gradually decreases upto $480 \mathrm{~min}$. The banana slice of 1:6 sample to sugar syrup ratio had lowest drying rate in comparison to others. Drying rate of banana slice increases initially decreased with sugar syrup concentration then decreased gradually with increasing drying time.

\section{Conclusion}

Osmotic dehydration was conducted at sample to sugar syrup ratio of 1:2, 1:4 and 1:6; thickness of banana slice of $8.0 \mathrm{~mm}$ under sugar syrup concentrations of $50{ }^{\circ}$ Brix at room temperature. The partially osmotic dehydrated samples were further subjected hot air for final drying at the temperature of $60^{\circ} \mathrm{C}$. The study revealed that the percent moisture loss, weight loss and solid gain increased with increase in sugar syrup concentration $50^{0}$ Brix while decrease with sample to sugar syrup ratio and then increased. Osmotic drying rate was found highest in sample to sugar syrup ratio of 1:6 followed by $1: 2$ and lowest in 1:4 with constant slice thickness of $8 \mathrm{~mm}$ and sugar syrup concentration
$(50 \%)$.

\section{References}

1. Biswal, R.M., Bozorgmehr, K., Tompkins, F.D. and Liu, X. (1991). Osmotic concentration of green beans prior to freezing. J. Food Sci. 46:1008-1012.

2. Chandra, S. and Kumari, D. (2011). To Study the Effect of Sample to Sugar Syrup Ratio on Osmotic Dehydrated Banana Slices. Proceeding of the 45th Annual convention of ISAE and International symposium on water for agriculture held at Dr. PDKV, Akola (India) during January 17-19, 2011. P, 294 (DFE-3.20).

3. Contreras, J.M. and Smyrl, T.G. (1981). An evaluation of osmotic concentration of apple rings using corn syrup solids. Can. Insti. Food Sci. Technol. J. 14:301-314

4. Conway, J., Castaigne, F., Picard, G. and Vavan, X. (1983). Mass transfer considerations in the osmotic dehydration of apples. Can. Insti., Food Sci. Technol. J. 16(1):25-29.

5. Desai, U.T. and Kotecha, P.M. (1995). Fig. In: Handbook of fruit science and technology, ed. Salunkhe DK and Kadam SS. Marcel Dekker, New York, pp. 407-417,

6. Flink, J.M. (1979). Dehydrated carrot slices: Influence of osmotic concentration on drying behaviour and product quality. In: Food Process Engineering, pp. 412-418. Linko, P., Malki, Y., Olkku, J., Larinkari, J., Fito, P., Ortega, E. and Barbosa, G. Eds., Applied Science Publishers, London.

7. Gekas, V. and Mavroudis, N. (1998). Mass transfer properties of osmotic solutions. II. Diffusivities. Intern. J. Food Properties. 1(2): 181-195.

8. Heng, K., Guilbert, S. and Cug, J.L. (1990). Osmotic dehydration of papaya. Influence of process variables on the product quality. Sci. des Alimentos. 10:831-848.

9. Islam, M.N. and Flink, J.N. (1982). Dehydration of potatoes: Osmotic 
concentration of food prior to freezing. J. Food Technol. 07: 387-403.

10. Kaymak-Ertekin, F, and Sultanoglu, M. (2000). Modeling of mass transfer during osmotic dehydration of apples. J. Food Eng. 46:243-250.

11. Ponting, J.D., Watters, G.G., Forrey, R.R., Jackson, R. and Stanley, W.L. (1966). Osmotic dehydration of fruits. Food Technol. 20: $125-128$

12. Prothon, F., Ahrne, L. and Sjoeholm, I. (2003). Mechanisms and prevention of plant tissue collapse during dehydration: a critical review. Critical Rev. Food Sci. Nutri. 43(4): 447-479.

13. Rastogi, N.K. and Raghavarao, K.S.M.S. (1997). Water and solute diffusion coefficients of carrot as a function of temperature and concentration during osmotic dehydration. J. Food Eng. 34:429-440.

14. Sharma, K., Steven, J.J., Syed S.H. Rizvi (2000). Food Process Engineering: A John Wiley \& Sons, Inc Publication.

15. Sharma, R.C., Joshi, V.K., Chauhan, S.K., Chopra, S.K. and Lal, B.B. (1991). Applications of osmosis-osmo-canning of apple rings. J. Food Sci. Technol. 28:86-88.

16. Somogyi, L.P., Ramaswamy, H.S. and Hui, Y.H. (1996). Processing of fruits: Science and technology, Vol. 1, Biology, principles, and applications, Technomic, Lancaster and Basel.

17. Videv, K., Taucher, S., Sharma, R.C. and Joshi, V.K. (1990). Effect of sugar syrup concentration and temperature on the rate of osmotic dehydration of apples. J. Food Sci. Technol. 25:307-308. 